\title{
O Ensino de Italiano no Espírito Santo: um Breve Panorama do Núcleo de Línguas da UFES
}

\author{
Janine Cestaro* \\ KYRIa FinARDI
}

RESUMO: Este trabalho analisa o ensino de italiano no Núcleo de Línguas (NL) da Universidade Federal do Espírito Santo (UFES) ao longo dos quatorze anos de sua oferta. Com esse objetivo, dados do número de turmas ofertadas foram levantados do sistema do NL desde 2003 com vistas tanto a descrever o percurso histórico do curso quanto suas demandas atuais, visando estabelecer índices de continuidade e abandono nos variados níveis em relação a horários, materiais didáticos utilizados e quadro de professores. O estudo usa uma metodologia mista com dados quantitativos e qualitativos, triangulados a fim de melhor entender o ensino de italiano nesse contexto. De maneira geral, os resultados sugerem que o curso de italiano do NL ocupa uma posição periférica em relação aos outros cursos de línguas estrangeiras ofertados pela instituição e aos cursos de italiano da Associação de Língua e Cultura Italiana do Espírito Santo (ALCIES) em Vitória. Com base nos resultados do estudo, concluímos com algumas sugestões para o ensino de italiano nesse contexto.

PALAVRAS-CHAVE: Língua italiana; Núcleo de Línguas - UFES; Ensino de italiano no ES.

ABSTRACT: The study analyzes the teaching of Italian in the Nucleus of Languages (NL) of the Federal University of Espirito Santo (UFES) during the fourteen years of its offer. With that aim, data on the number of classes offered were collected from the NL system since 2003 with a view to describe the historical course of the offer and its current demands, aiming to establish indices of continuity and abandonment in the various levels in relation to schedules, didactic materials and teachers. The study uses a mixed methodology with quantitative and qualitative data triangulated in order to better understand the teaching of Italian in this context. In general, the results suggest that the Italian course of the NL occupies a peripheral position in relation to the other

*Universidade Federal do Espírito Santo, Vitória (Brasil) - janinecestaro@gmail.com / 
foreign language courses offered by the institution and other the offer of Italian courses of the Espírito Santo Italian Language and Culture Association (ALCIES) in Vitória. The study concludes with some suggestions for the teaching of Italian in this context.

KEYWORDS: Italian language; Nucleus of Languages - UFES; Teaching Italian in $E S$.

ABSTRACT: Questo lavoro analizza l'insegnamento dell'italiano presso il Núcleo de Línguas (NL) dell'Università Federale di Espirito Santo (UFES) nel corso dei quattordici anni dal suo inizio. A tal fine, sono stati analizzati $i$ dati presenti nel sistema del Núcleo de Línguas dal 2003 al fine di descrivere sia il percorso storico del corso sia le sue esigenze più attuali. Sono stati inoltre verificati i dati relativi al numero di corsi offerti nel corso degli anni al fine di stabilire quali siano stati $i$ tassi di continuità e di abbandono ai vari livelli in relazione agli orari, ai materiali didattici utilizzati e al corpo docente. Lo studio utilizza una metodologia mista con dati quantitativi e qualitativi, associati al fine di comprendere meglio l'insegnamento dell'italiano in questo contesto. In generale, i risultati suggeriscono che il corso italiano NL occupa una posizione periferica rispetto agli altri corsi di lingua straniera offerti dall'istituzione e altri corsi di italiano di l'Associazione di Lingua e Cultura Italiana dello Spirito Santo (ALCIES) in Vitória. Sulla base dei dati raccolti e analizzati nello studio, concludiamo con alcuni suggerimenti per insegnare l'italiano in questo contesto.

PAROLE CHIAVE: Lingua italiana; Núcleo de Línguas - UFES; Insegnamento dell'italiano in ES.

Una lingua diversa è una diversa visione della vita.

(Federico Fellini) 


\section{Introdução}

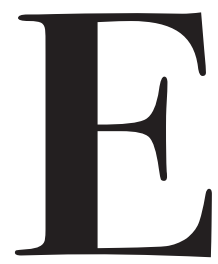

ste estudo foi motivado pelo desejo de compreender a aparente desproporção existente entre a forte presença de imigrantes italianos no Espírito Santo, por um lado, e a baixa procura por cursos desse idioma no estado, por outro. Embora o Espírito Santo esteja entre os estados com maior percentual de descendentes de italianos, tendo inclusive a cidade de Santa Teresa sido reconhecida pelo governo federal (Lei $n^{\circ} 13.617$, de 11 de janeiro de 2018) como a primeira cidade fundada por imigrantes italianos no país, a procura pelo estudo da língua italiana está aquém das expectativas para o estado. Essa constatação, por sua vez, surgiu da observação de que entre as línguas oferecidas pelo Núcleo de Línguas (NL) da Universidade Federal do Espírito Santo (UFES), única Universidade Federal do estado, o italiano é a língua menos procurada, ficando bem atrás do francês, por exemplo, ainda que o ES não tenha nenhuma relação histórica evidente com países francófonos. Dito isso, justificamos a escolha pelo NL como contexto para iniciar nossa jornada rumo a um melhor entendimento do fenômeno do ensino-aprendizado de italiano no ES.

A primeira oferta de italiano no NL foi feita em 2003, razão pela qual escolhemos o recorte temporal de 2003-2017 para nossa análise observando o perfil do curso de italiano do NL nesse período e comparando seus dados com os da Associação de Língua e Cultura Italiana do Espírito (ALCIES).

\section{A imigração italiana no Espírito Santo}

Historicamente, Brasil e Itália apresentam interfaces em relação à mobilidade populacional. A partir dos anos 80, em razão das dificuldades socioeconômicas enfrentadas pelo Brasil, muitos brasileiros partiram para o "Belpaese", em busca de trabalho e melhoria de vida. Segundo dados do Instituto Nacional de Estatística (Istat), havia 45.410 brasileiros vivendo legalmente na Itália em 2016 (ISTAT, 2016).

A imigração no estado do Espírito Santo teve início em 1812 com a fundação da Colônia de Santo Agostinho, atualmente município de Viana. Nesse período, os imigrantes eram açorianos que chegaram a nossas terras através de um empreendimento oficial de colonização agrícola criado pelo então governador Rubim. Em 1847 foi fundada a Colônia Imperial de Santa Isabel, 
localizada às margens do Rio Jucu, onde chegaram outros imigrantes de origem europeia, entre os quais alemães da Renânia e sardos do então reino Sardo Piemontês (Itália). A partir de 1857, com a fundação da Colônia de Santa Leopoldina, existem registros da entrada de suíços, e de pessoas provenientes da Província da Pomerânia (então sob o domínio do Império Prussiano), da Saxônia, Baden, Bavária, Hesse, Renânia; da Holanda; de Luxemburgo; da França e da Áustria (www.ape.es.gov.br/imigrantes/html/historico).

A sanção da Lei Áurea em 1888 produziu um crescimento significativo do número de imigrantes que eram direcionados para fazendas com o objetivo de substituir a mão de obra escrava no cultivo de café. No que diz respeito à imigração italiana, o marco histórico foi a chegada do vapor La Sofia em 17 de fevereiro de 1874, com 388 famílias (FRANCESCHETTO, 2014. p. 19). O navio fazia parte da Expedição Tabachi, que através da promessa de terras férteis e ouro agenciou italianos para o trabalho nas lavouras. A expedição Tabachi deu início a uma epopeia emigratória dos italianos para o Brasil. Fugindo de uma Itália recém-unificada, com altas taxas demográficas, grande número de desempregados, fome e miséria, os italianos depositaram no Brasil o sonho de uma nova vida. De acordo com Carneiro (1950), o Espírito Santo foi a Província imperial que recebeu a primeira remessa importante de emigrantes italianos. O resultado desse movimento migratório é ainda muito presente no Espírito Santo. De acordo com o sociólogo Renzo M. Grosseli no livro Italianos: Base de dados da imigração italiana no Espírito Santo nos séculos XIX e XX entre os séculos XIX e XX estima-se o registro de trinta e seis mil nomes de imigrantes italianos no estado. $O$ autor argumenta ainda que:

Foram realizados inúmeros e diversos cálculos a propósito, mas é um fato quase unanimemente aceito que o Estado da região Sudeste conte hoje com o maior percentual de população de ascendência italiana. Dispõe-se de resultados de pesquisas que indicam uma cifra ligeiramente inferior a 50\% à população capixaba de ascendência italiana. Outras apontam 65\%, contra, por exemplo, os 60\% de Santa Catarina, menos de 40\% do Paraná, $30 \%$ de São Paulo e $22 \%$ do Rio Grande do Sul. (FRANCESCHETTO, 2014, p. 19)

Embora o ponto de chegada desses imigrantes, a partir da Expedição Tabachi, tenha sido Santa Cruz (Aracruz), eles depois se dispersaram, sobretudo pelo interior do estado onde fundaram colônias, como, por exemplo, Santa Teresa, Castelo, Ibiraçu, Rio Novo, Alfredo Chaves, Nova Venécia, Venda Nova do Imigrante e Colatina.

Por esse motivo, a população do Espírito Santo tem um laço estreito com a cultura italiana mantendo, inclusive, festas tradicionais como a Festa do Imigrante, em Santa Teresa, a Festa da Polenta em Venda Nova e a Festa Italiana de Castelo, só para mencionar algumas.

Conforme expusemos na introdução deste artigo, a forte presença italiana no estado até os dias de hoje não é proporcional à procura pelo estudo da língua italiana no NL, razão que motivou este estudo. A oferta de cursos de italiano em Vitória se limita à do NL (único núcleo de línguas do estado), à da ALCIES e outras poucas escolas privadas. Os capixabas representarem mais de 50\% das solicitações de serviços do consulado geral da Itália no Rio justificando a tão sonhada vinda de uma unidade consular para o estado, projeto esse que parece ter recebido 
atenção do governo do estado finalmente em 2017.

A fim de melhor entender a demanda pelo italiano no ES em geral e no NL da UFES especificamente, um estudo foi realizado adotando uma metodologia mista (DORNYEI, 2007) para analisar e triangular dados qualitativos e quantitativos relativos à oferta do ensino de italiano nesse contexto. $\mathrm{O}$ estudo tem também caráter exploratório e descritivo uma vez que lança mão de um levantamento bibliográfico e documental realizado em bancos de dados do NL e da ALCIES.

\section{O estudo da língua italiana no ES}

O ensino da língua italiana na rede pública do ES, sempre foi bastante tímida, com apenas dois municípios capixabas apresentando esse idioma em seus currículos: Santa Teresa e Domingos Martins, mesmo antes da reforma educacional de 2017. Com a conversão da Medida Provisória 746, de 2016 na Lei 13.415 de 2017 o ensino de inglês se tornou obrigatório na educação básica pública afetando a oferta de outros idiomas, inclusive a de italiano.

Além da política linguística expressa na supramencionada lei, outro fator que pode ter contribuído para a pequena oferta de italiano na rede pública capixaba é a escassez de professores licenciados na área. O curso de dupla licenciatura Português-Italiano da Universidade Federal do Espírito Santo, única Universidade Federal do estado e única licenciatura de italiano do estado, possui oferta irregular tendo aberto vagas somente duas vezes: a primeira, em 2013/1 e a segunda em 2016/1. Com apenas dois professores permanentes de italiano, a UFES não dá conta de manter uma oferta constante do curso de Letras Português-Italiano e como não há nenhum professor de italiano na pós-graduação, a oferta de projetos de pesquisa, tanto na graduação e principalmente na pós, fica limitada à oferta feita por professores de áreas afins, sem formação específica em italiano. Assim, a formação de professores e pesquisadores na área de italiano é ainda limitada no estado. A oferta de cursos livres de italiano se limita basicamente ao Núcleo de Línguas da UFES e à ALCIES que ofertam cursos de italiano para a comunidade em geral.

\section{O Núcleo de Línguas}

O Núcleo de Línguas: Ensino, Extensão e Pesquisa da Universidade Federal do Espírito Santo foi regulamentado pela resolução $n^{\circ} 39 / 2016$, de 14 de outubro de 2016 “...e tem como meta promover atividades e serviços voltados para o ensino aprendizagem de línguas, por meio da indissociabilidade entre ensino, extensão e pesquisa e na perspectiva do plurilinguismo e da multiculturalidade, com o envolvimento dos cursos de graduação e pós-graduação da UFES" (CEPE, Resolução 39/2016).

O programa Cursos de Línguas oferece atualmente, como cursos regulares, seis idiomas: alemão, espanhol, francês, inglês, italiano e português para estrangeiros. Os cursos apresentam 
conteúdo sequencial programado em grau crescente de dificuldade e asseguram que os alunos tenham condições de iniciar e concluir o curso, por meio da oferta dos níveis necessários. Até o segundo semestre de 2012, os cursos seguiram as nomenclaturas de Básico, Intermediário e Avançado. Após o período referido, os cursos passaram a ser organizados em níveis conforme o Quadro Comum Europeu de Referência para as Línguas (QECRL)1. Criado pelo Conselho da Europa em 2001, esse quadro é um documento internacionalmente reconhecido que tem como objetivo determinar, por meio de critérios claros e objetivos, os variados níveis de aprendizado de línguas.

No segundo semestre de 2017, os alunos matriculados nos cursos regulares de alemão, espanhol, francês, inglês e italiano perfaziam um total de 4.974, sendo 4.273 pagantes e 701 bolsistas, divididos em 293 turmas. Inglês liderava a lista dos cursos com maior número de inscritos com 3.123 alunos matriculados. Desse montante, 2.674 eram pagantes e 449 eram bolsistas. Surpreendentemente, francês ocupava o segundo lugar no ranking das línguas mais estudadas no NL, contabilizando 752 alunos, sendo 651 pagantes e 101 bolsistas. Em terceiro lugar, estava o curso de espanhol, com 404 alunos, total que se dividia em 322 pagantes e 82 bolsistas. Alemão assumia o quarto lugar com 374 estudantes dos quais 341 eram pagantes e 33 bolsistas. O curso de italiano ocupava o quinto e último lugar na classificação, com um total de 321 alunos, sendo 285 pagantes e 36 bolsistas (NL, Sistema Oaasis, 2017).

Considerando esses números em relação ao total de alunos, sem diferenciar pagantes e bolsistas, percentualmente, inglês detinha $62,78 \%$ do total do número de alunos inscritos, seguido pelo francês com 15,11\%, o espanhol ocupava o terceiro lugar, com $8,12 \%$. Em quarto lugar, destacava-se o curso de alemão com $7,51 \%$, seguido por italiano com $6,45 \%$. Se a análise considerar somente o número de alunos pagantes, inglês, francês e italiano mantêm a mesma ordem de classificação, isto é, primeiro, segundo e quinto lugar respectivamente. Porém, ocorre uma inversão entre espanhol e alemão: nessa perspectiva, alemão passa a ser o terceiro idioma em números de alunos pagantes e espanhol assume o quarto lugar. Isso ocorre porque percentualmente, considerando o número de bolsistas, espanhol supera todos os outros idiomas. Com o percentual de $20,29 \%$ é o idioma com maior número de bolsistas, seguido do inglês com $14,37 \%$, do francês com $13,43 \%$, do italiano com $11,21 \%$ e do alemão com $8,82 \%$.

É importante esclarecer que o Núcleo de Línguas apresenta um programa semestral de distribuição de bolsas. A quantidade de bolsas é calculada a cada semestre, proporcionalmente ao número de alunos inscritos nos cursos, o que significada $10 \%$ do total das vagas. Parte dessas bolsas pertence ao próprio NL e, de acordo com a resolução do Conselho Universitário, são destinadas aos estudantes da UFES, professores e técnicos administrativos da UFES e estudantes de ensino médio da rede pública de ensino. No caso dos estudantes, professores e técnicos administrativos da UFES, a gestão do benefício é feita por órgãos da universidade tais quais as Pró-reitorias de Graduação - Prograd, de Extensão - Proex, de Pesquisa e Pós-graduação - PRPPG e de Assistência Estudantil - Proaeci. Já as bolsas destinadas à rede pública de ensino são distribuídas para estudantes regularmente matricula-

1 Disponível em: <http://cvc.instituto-camoes.pt/fichaspraticas/formulario/quadro_niveiscomuns.html>. 
dos em escolas de ensino médio da rede pública, municipal, estadual ou federal, por meio de sorteio. É permitida apenas uma bolsa por família de renda comprovada de até quatro salários mínimos. Além disso, parte das bolsas é gerenciada pela própria universidade, por meio de suas pró-reitorias com critérios próprios.

\section{O curso de italiano do Núcleo de Línguas}

O curso de italiano no NL tem duração de quatro anos/oito semestres com carga horária de 51 horas semestrais e foi ofertado pela primeira vez no segundo semestre de 2003. Os níveis do curso estão divididos da seguinte maneira: os níveis Italiano 1 e Italiano 2 referem-se ao nível A1 de equivalência do QECRL, enquanto os cursos de Italiano 3 e Italiano 4 inserem-se na categoria A2, e assim por diante sendo os níveis Italiano 5 e 6 equivalentes ao B1 e os dois últimos, 7 e 8, ao B2 (CEPE, Resolução no 47/20062016).

No primeiro semestre da oferta de italiano foram abertas três turmas, disponibilizando 60 vagas, das quais 49 foram preenchidas. Um ano depois, em 2004/2, o curso tinha o dobro de turmas com 72 alunos (NL, Sistema Oaasis, 2017).

A capacidade máxima de alunos por turma é de 20 alunos. O levantamento do total de turmas ofertadas a cada semestre do curso desde o seu início assim como a quantidade de vagas preenchidas foi levantado no sistema Oaasis do NL para este estudo. Considerando especificamente o número de alunos inscritos a cada semestre obtivemos o seguinte panorama: o crescimento do curso de italiano foi progressivo até o segundo semestre de 2007. Nesse período, o número de alunos passou de 49 (2003/2) para 336 (2007/2), o que indica um crescimento de $585 \%$, quase sete vezes mais que em 2003. Analisando todos os semestres vemos que 2016/1 registrou o maior índice de alunos matriculados, contabilizando 351 estudantes.

Considerando os quatorze anos da oferta do curso de italiano do NL, a média de alunos inscritos é de 273,1 estudantes por ano. O ano de 2007 representou um marco no desenvolvimento do curso. A partir desse período, somente em duas ocasiões (2011/1 e 2013/2) o número de alunos matriculados foi inferior a 300. Assim, temos que de 2007 a 2017, a média de alunos matriculados por semestre é de aproximadamente 316.

Esses dados sugerem que o público de italiano se mantém estável, com raras exceções quando sendo inferior a 300 alunos e em somente um momento superando os 350 . Ao analisarmos a situação das turmas de italiano desde o início da oferta podemos reiterar que foram ofertadas de 2003 até o momento 527 turmas, das quais, 148 referem-se ao nível 1, 114 ao nível 2, 76 ao nível 3,53 ao nível 4, 41 ao nível 5, 30 ao nível 6, 25 ao nível 7 e 23 ao nível 8. O número decrescente de turmas em relação ao aumento dos níveis é normal, tendo em vista que os alunos tendem a desistir com o aumento das exigências e o nível de dificuldade. Assim, em geral a oferta do nível 1, em tese, é sempre maior do que a de nível 2 e assim por diante, até o nível 3. Já nos níveis 4, 5 e 6 essa oscilação ocorre em menor grau.

Dessa forma, considerando a oferta semestral percebemos que, de 2003/2 até 2017/2, foram 
ofertadas em média, 5,10 turmas de iniciantes por semestre com uma média de 1,15 turmas que concluem o Italiano 8. Em síntese, a cada cinco turmas abertas, apenas uma conclui o curso.

Analisando o total de turmas ofertadas em cada nível durante todos os anos da oferta de italiano no NL, observamos que na passagem do nível 1 para o nível 2, 97,2\% das turmas são mantidas, o que indica o cancelamento de apenas $2,7 \%$, o menor índice de cancelamento comparado aos outros semestres do curso. A maior manutenção de turmas é entre os dois primeiros e os dois últimos semestres do curso. Entre os níveis Italiano 6 e 7, percebemos que, percentualmente, $83,3 \%$ das turmas têm continuidade, enquanto na passagem do Italiano 7 para o 8 , esse percentual aumenta para $92 \%$, sendo o índice de cancelamentos de $16,6 \%$ e $8 \%$, respectivamente.

Já o maior índice de redução de turmas ocorre na transição do nível 2 para o nível 3, onde apenas $66,6 \%$ das turmas permanecem, isto é, são cancelados $33,3 \%$ dos grupos. O segundo índice de cancelamento mais alto é na transição do nível 3 para o 4, com índice de 30,2\%. Nos níveis 4 e 5 a taxa de permanência é de $77,35 \%$, contra 22,64\% de cancelamentos enquanto a transição entre os níveis 5 e 6 aponta 73,17\% de manutenção contra 26,83\% de redução.

Após a análise das turmas ofertadas, faz-se necessário compreender como esses percentuais se revelam se pautados no número de alunos. Com esse objetivo foi feito um levantamento da quantidade de alunos inscritos em cada semestre do curso no período de 2003 a 2017. Considerando o total de alunos que ingressam no curso, a parcela de alunos que conclui o curso é modesta. Até o segundo semestre de 2017, o número de alunos inscritos no nível 1 foi de 2594 e desses, apenas 296 concluíram o nível 8. Isso indica que um percentual de 11,41\% finaliza o curso ou que $88,59 \%$ dos inscritos não conclui o último nível.

O maior índice de desistência ocorre na passagem do nível 1 para o nível 2. Nesse estágio, observamos que 62,56\% dos alunos se mantêm no curso. Embora mais da metade prossiga, é necessário observar que o índice de desistência no período é de aproximadamente $37,43 \%$. Acreditamos que a desistência esteja relacionada a mais de um fator. Em primeiro lugar destacamos o fato do ensino de italiano ser optativo e, portanto, questões de incompatibilidade de horários afeta a permanência de alunos ao longo dos semestres e do curso uma vez que os cursos raramente mudam de horário, mas a disponibilidade do público varia a cada semestre. Outra razão que pode afetar a procura e permanência de alunos nos cursos de italiano do NL se relaciona ao objetivo de professores e alunos. O curso do NL é voltado para o desenvolvimento de proficiência nas habilidades de compreensão e produção (oral e escrita) sendo que alguns alunos podem ter objetivos diversos, de, por exemplo, desenvolver apenas a habilidade de compreensão e produção oral a fim de se comunicar na língua para viagens.

Situação semelhante ocorre na passagem do nível 2 para o nível 3, onde a taxa de desistência é de $32,34 \%$ e a de continuidade é de $67,65 \%$. O número de alunos no $3^{\circ}$ semestre costuma ser de menos da metade dos que iniciaram o curso. Entre o primeiro e o terceiro semestre há uma taxa de diminuição de $57,68 \%$ do número de alunos. No quarto semestre, ou seja, na metade do curso, o índice de evasão é de 70,27\%. Se analisarmos a inferência feita acima, sobre 
os objetivos dos alunos ao procurar o curso de italiano, podemos sugerir que os alunos que procuram o curso para desenvolver uma habilidade de compreensão e produção oral básica que seja suficiente para "se virar" no italiano, não se sentem motivados a continuar o curso depois da metade quando a gramática já começa a ficar mais complexa, aumentando a dificuldade. Para os alunos que não tem interesse em melhorar a gramática, o estudo de italiano no NL pode perder a motivação e interesse depois do terceiro semestre.

Após o nível 4 os índices de evasão tendem a diminuir, sendo de 28,40\% na passagem do nível 4 para o nível 5,23,91\% entre os níveis 5 e 6,24,76\% na transição do nível 6 para o nível 7 e apenas $6,32 \%$ na transição entre os últimos dois níveis, do 7 para o 8. Novamente inferimos que os que ficam depois da metade do curso são os que querem melhorar seu nível de proficiência e gramática nas quatro habilidades básicas de compreensão e produção oral e escrita enquanto os que fazem apenas os primeiros semestres possivelmente estejam mais interessados em desenvolver um índice de fluência básica no idioma.

Em síntese, destacamos que, o curso de italiano do NL, tem a menor procura entre os cursos ofertados no NL, ou seja, inglês, francês, espanhol e alemão, aqui citados na ordem de maior para menor procura, além de ter altos índices de evasão, o que possivelmente está ligado ao objetivo do estudo de italiano. Enquanto os outros idiomas ofertados no NL são em geral estudados por necessidade (inclusive acadêmica), os que procuram o italiano, segundo Cestaro (2017) o procuram por prazer, deixando o curso quando deixam de ter prazer no aprendizado, em geral quando o ensino começa a ficar mais complexo com as regras de gramática e a cobrança semelhante à dos outros idiomas.

\section{ALCIES}

Outra instituição responsável pelo ensino da língua italiana no estado é a ALCIES, apoiada pelo artigo 636, do Decreto Legislativo italiano 297/94 (ex-Lei 153/71) (ITALIA, 2015) que determina que a difusão da língua italiana no exterior constitui um dos objetivos principais do Ministério das Relações Exteriores e da Cooperação Internacional da Itália. De acordo com esse decreto, o Estado Italiano compromete-se a promover cursos de Língua e Cultura Italiana onde existam filhos e descendentes de italianos, desenvolvendo as suas atividades por meio dos institutos italianos de cultura e de escolas italianas ou bilíngues. Cerca de 300.000 indivíduos são beneficiados com os cursos promovidos pela Itália no exterior e a ALCIES se encaixa nesse contexto.

Como entidade sem fins lucrativos, a ALCIES tem como principal mantenedor o governo italiano, por meio do Ministério das Relações Exteriores e da Cooperação Internacional e do Consulado Geral do Rio de Janeiro. A ALCIES oferece diversos tipos de cursos com cargas horárias e objetivos variados além de ser responsável pelo ensino de italiano nas escolas públicas, sobretudo do interior e conta atualmente com pouco mais de 2.500 alunos entre crianças e adultos. 
Os dados analisados em relação à ALCIES referem-se ao intervalo entre 2010 e 2018. Em 2010, a instituição contava com um total de 187 inscritos nos diversos cursos. A quantidade de alunos sofreu uma leve redução nos anos de 2011 (165 alunos) e 2012 (144 alunos), refletindo as dificuldades econômicas da Itália que no fim de 2012 resultou no corte de verbas do Ministério das Relações Exteriores e da Cooperação Internacional destinadas às associações italianas no exterior. Considerando os anos 2010, 2011 e 2012, a média de alunos inscritos na Instituição era de 165 alunos ao ano, o que nos permite afirmar que em 2018 os números voltaram a se estabilizar, contabilizando 169 inscritos atualmente.

Entretanto e conforme se previa depois da reforma educacional de 2017, essa melhora não é observada na oferta de italiano na rede pública. De acordo com a ALCIES, em 2009, o ensino de italiano na rede pública de ensino era ofertado nas escolas municipais de Domingos Martins, Vargem Alta e Nova Venécia. Graças ao convênio firmado entre as prefeituras e a ALCIES os alunos tinham a possibilidade de estudar a língua italiana no contraturno. Em 2011, três escolas de ensino fundamental de Venda Nova também incluíram italiano em suas atividades. Outros municípios também se uniram à ALCIES e se beneficiaram desse acordo como Vitória, Vila Velha, Cachoeiro do Itapemirim, Alfredo Chaves e Castelo.

Segundo os dados fornecidos pela instituição em relação ao número de alunos inscritos na rede pública de ensino entre 2010 e 2018 em 2010, um total 4.509 alunos da rede pública municipal estudavam gratuitamente a língua italiana, por meio dos convênios entre a ALCIES e as prefeituras sendo que entre 2010 e 2015 , os números reduziram gradativamente. $\mathrm{O}$ ano de 2015 registrou o número mais baixo de alunos atendidos pelos convênios, com um total de 2062, menos da metade dos estudantes de 2010. Em 2016 e 2017 foi observada uma modesta melhora, com 2.324 e 2.613 alunos respectivamente, porém em 2018 os números voltaram a cair, apontando 2.358 inscritos.

Se compararmos a oferta da ALCIES com a do NL e considerando os motivos que afetaram essa oferta no lapso temporal analisado (crise na Itália e reforma educacional de 2017 na rede pública), podemos dizer que a oferta na ALCIES se mantém mais estável do que a do NL e que o índice de redução de turmas da ALICES é menor do que a do NL. Uma possível razão para isso está no fato da ALCIES ofertar diversos tipos de cursos com cargas horárias e objetivos variados, sendo, portanto, mais flexível do que a oferta do NL que oferece apenas um tipo de curso (para fins gerais) com a mesma carga horária e objetivos desde o nível 1 até o 8.

\section{Conclusão}

Este estudo partiu do pressuposto de que a realidade linguística do ES não corresponde à expectativa em relação à procura pelo aprendizado do italiano no ES. Sendo o ES um estado com um passado histórico tão ligado à Itália, com tantas memórias e referências culturais, pensamos que ele deveria ser um lugar privilegiado para o ensino-aprendizado de italiano. A baixa procura pelo ensino de italiano no ES motivou este estudo que teve como objetivo compreender 
esse fenômeno no contexto do NL da UFES.

A análise da oferta de italiano no NL mostrou que a taxa de desistência ao longo do curso pode estar relacionada ao tipo de oferta feita no NL uma vez que o italiano é ofertado nos mesmos moldes dos outros idiomas. Ao contrário do que ocorre com o estudo dos outros idiomas, foi sugerido aqui e em outro estudo realizado no NL (CESTARO, 2017), que o objetivo para o estudo do italiano estaria mais relacionado ao prazer do que à necessidade acadêmica. Assim, uma sugestão para aumentar a procura pelo italiano no estado e no NL especificamente é ofertar cursos mais flexíveis (vide ALCIES), tais como cursos de conversação livre, onde o objetivo não seria “formar" alunos, mas antes permitir sua expressão livre e prazerosa na língua italiana.

É longo o caminho para compreender o que fez com que o italiano, língua de imigração, fosse aos poucos se tornando menos interessante que outras línguas no panorama linguístico do Espírito Santo e especificamente no NL da UFES. Tendo em vista o cenário nacional em face da Lei 13.415 que torna o ensino de inglês obrigatório no Brasil e de acordo com sugestões de Finardi (2017) é importante ressaltar a urgência de pensarmos em políticas linguísticas que sejam mais multilíngues e inclusivas.

Independente da oferta de cursos variados de italiano para a população em geral, pensamos que um maior apoio do governo do estado para valorizar a importância histórica da cultura italiana e instituir o ensino da língua na rede pública seja necessário. Nesse sentido, esperamos que a promessa de trazer o consulado da Itália para o ES se concretize. De acordo com os Parâmetros Curriculares Nacionais (PCNs), as diretrizes criadas pelo Governo Federal para a orientação de educadores e elaboração dos currículos escolares em todo país, são três os critérios fundamentais para a inclusão de uma língua estrangeira no currículo escolar: fatores históricos, fatores relativos às comunidades locais e fatores relativos à tradição. (BRASIL, 1998, p. 22). No que concerne o Espírito Santo, o segundo fator garantiria a inserção do italiano nas escolas, uma vez que, como definem ainda os PCNs:

A convivência entre comunidades locais e imigrantes ou indígenas pode ser um critério para a inclusão de determinada língua no currículo escolar. Justifica-se pelas relações envolvidas nessa convivência: as relações culturais, afetivas e de parentesco (BRASIL, p. 23).

Finalmente, apontamos ainda a necessidade de garantir a oferta contínua de vagas para o curso de Letras Português/Italiano da UFES com consequente fortalecimento da formação de professores no estado.

\section{Referèncias}

ALCIES: Associação de Língua e Cultura Italiana do Espírito Santo. Projeto para implantação do ensino de língua e cultura italiana nas escolas públicas municipais de vitória. Vitoria.

BRASIL. Secretaria de Educação Fundamental. Parâmetros Curriculares Nacionais/Secretaria de Educação Fundamental. Brasília: MEC/SEF, 1998.

Lei n. 9.394, de 20 de dezembro de 1996, de Diretrizes e Bases da Educação Nacio- 
nal. Brasília, DF, 20 dez. 1996. Disponível em: <http://www2.camara.leg.br/legin/fed/lei/1996/lei-9394-20-dezembro-1996-362578-publicacaooriginal-1-pl.html>. Acesso em: 11. nov. 2018.

. Lei de Diretrizes e Bases da Educação Nacional. Lei n ${ }^{\circ}$ 13.415/2017, de 13 de fevereiro de 2017. Disponível em: <http://www.planalto.gov.br/ccivil_03/_ato2015-2018/2017/lei/L13415.htm>. Acesso em: 10 nov. 2017.

. Lei n. 13.617, de 11 de janeiro de 2018. Disponível em: <http://www2.camara.leg.br/legin/fed/ lei/2018/lei-13617-11-janeiro-2018-786097-publicacaooriginal-154753-pl.html>. Acesso em: 10 nov. 2018.

CARNEIRO, J. F. Imigração e colonização no Brasil. Rio de Janeiro: Faculdade Nacional de Filosofia, Cadeira de Geografia do Brasil, 1950, Publicação Avulsa, 2.

CESTARO, J. O ensino de italiano no núcleo de línguas da UFES. Vitória: Trabalho de conclusão de curso não publicado. Letras Português/Italiano, Universidade Federal do Espírito Santo, 2017. Disponível em: <https://blog.ufes.br/kyriafinardi/files/2018/01/CESTARO-Janine-Cunha-TCC-Licenciatura-Letras-Portugu\%C3\%AAs-Italiano-2017-2.pdf>. Acesso em 11 nov. 2018.

CONSELHO DE ENSINO, PESQUISA E EXTENSÃO DA UNIVERSIDADE FEDERAL DO ESPÍRITO SANTO. Resolução $n^{\circ}$ 39/2016, de 14 de outubro de 2016. Disponível em: $<$ http://200.137.65.195/siteclinguas/arquivos/instrucoes_normativas/resolucao_39.2016CEPE_regulamento\%20do\%20nucleo\%20de\%20linguas.pdf > Acesso em: 2 set. 2017.

CONSELHO UNIVERSITÁRIO DA UNIVERSIDADE FEDERAL DO ESPÍRITO SANTO (Bra-

sil). Resolução $n^{\circ}$ 47/2006, de 21 de dezembro de 2006. Disponível em:

$<$ http://www.daocs.ufes.br/sites/daocs.ufes.br/files/field/anexo/resolucao_47.2006_com_anexo. pdf>. Acesso em: 2 set. 2017.

. Resolução no 32/2000. Disponível em: <http://daocs.ufes.br/sites/daocs.ufes.br/files/ field/anexo/resolucao_32_2000.pdf>. Acesso em: 2 set. 2017.

DORNYEI, Z. Research methods in applied linguistics: Quantitative, qualitative and mixed methodologies. Oxford: Oxford University Press. 2007.

FINARDI, K. What Brazil can learn from Multilingual Switzerland and its use of English as a Multilingua Franca. Acta Scientiarum (UEM), v. 39, p. 219-228, 2017.

FRANCESCHETTO, C. Italianos: base de dados da imigração italiana no Espírito Santo nos séculos XIX e XX. Vitória: Arquivo Público do Estado do Espírito Santo, 2014. Disponível em: <https://ape. es.gov.br/Media/ape/PDF/Livros/italianos.pdf>. Acesso em: 3 set. 2017.

ITALIA. Documento LXXX, n.3. Relazione sull'attività svolta per la riforma degli istituti italiani di cultura e gli interventi per la promozione della cultura e della lingua italiane all'estero. 28 dez. 2015. Disponível em: <http://www.camera.it/_dati/leg17/lavori/documentiparlamentari/indiceetesti/080/003/ INTERO.pdf>. Acesso em: 12 abr. 2018.

NÚCLEO DE LÍNGUAS: ENSINO, EXTENSÃO E PESQUISA. Sistema Oaasis. 2017. . Bolsas. 2018c. Disponível em: http://www.nucleodelinguas.ufes.br/bolsas. Acesso em: 10 de Nov. 2018.

Quadro Europeu Comum de Referência para as Línguas - Aprendizagem, ensino, avaliação. Porto, Edições ASA, 2001. Disponível em: <http://cvc.instituto-camoes.pt/fichaspraticas/formulario/quadro_niveiscomuns.html>. Acesso em 24 set.2017.

Recebido em: 19/06/2018

Aprovado em: 09/11/2018 